\title{
Effects of Motivational Adaptive Instruction on Student Motivation Towards Mathematics in a Technology-Enhanced Learning Classroom
}

\author{
Shu Ling Wong \\ Faculty of Educational Studies, Universiti Putra Malaysia, Malaysia \\ ORCID: 0000-0002-4295-4289 \\ Su Luan Wong \\ Faculty of Educational Studies, Universiti Putra Malaysia, Malaysia \\ ORCID: 0000-0001-7824-314X
}

Received: 24 Feb 2021

Accepted: 11 Aug 2021

\begin{abstract}
This quasi-experimental study sought to investigate the effects of the motivational adaptive instruction on Malaysian students' motivation towards mathematics in a technology-enhanced learning classroom. Geometer's Sketchpad is used in the study to foster a technology-enhanced learning environment. The motivationally adaptive instructions were designed following the Attention, Relevance, Confidence, and Satisfaction (ARCS) motivational model. The study adopted a non-equivalent control group design with pre-and posttest with two weeks of treatments. Two intact Form Two classrooms were randomly assigned to an experimental group and a comparison group - each with 20 students. The findings showed that Malaysian students had a slightly above-average level of motivation towards mathematics. The ANCOVA results showed that the intervention did not significantly improve the experimental group's students' motivation towards mathematics learning, despite having their motivation mean scores improve from Time 1 to Time 2. The results also showed that motivation and mathematics performance were not strongly correlated for this group of students. The weak relationship between motivation and mathematics performance among Malaysian students may be explained by the culture and value of East Asian towards education, which is discussed in this paper.
\end{abstract}

Keywords: motivation, mathematics, ARCS motivational model, Malaysia, Geometer's Sketchpad, dynamic geometrical software

\section{INTRODUCTION}

Mathematics is a mandatory subject for both primary and secondary education in Malaysia. Over the past decades, it was established that motivation plays a vital role in mathematics education (Hannula et al., 2016; Schukajlow et al., 2017; Walter \& Hart, 2009). As revealed by the Programme for International Student Assessment (PISA) 2012, students' motivation is closely related to mathematics performance. However, the relationship is at a higher level among outstanding students than those performed at a lower level (OECD, 2014). It was found that Malaysian eight-graders' underperformed mathematics results were closely related to their high level of anxiety and low self-efficacy in mathematics learning in the PISA 2012 (Thien \& Ong, 2015). In addition, the analyses done by Ismail (2009) further supported the significant relationship between self-confidence in mathematics and mathematics performance among Malaysian students by adopting results data from TIMSS 2003. These results affirm the importance of motivation reducing negative attitudes towards mathematics learning. A previous study also showed that mathematics anxiety could be reduced by improvising instructional strategies that further improve students' beliefs about mathematics (Kim \& Keller, 
2010; Schukajlow et al., 2017). As a measure to improve students' mathematics performance, Malaysian teachers are urged to refine and polish their instructional strategies to enhance students' self-efficacy and motivation to decrease students' anxiety in mathematics learning (Ismail \& Awang, 2012; Thien \& Ong, 2015).

Following that is the need to understand what motivation means in instructional design. Firstly, motivation is commonly defined as the forces that drive and direct one's behaviour towards the desired outcome (Dweck, 2017). It is generally known as extrinsic and intrinsic motivation (Deci \& Ryan, 2000). According to the self-determination theory extrinsically motivated students are engaged in the learning tasks for the separable rewards from the learning outcomes while intrinsically motivated students are inherently interested in the learning activity (Deci \& Ryan, 2008). Thus, motivational theorists claim that intrinsic motivation can result in high-quality learning. However, Brophy (2008) argues that school and classroom settings may not always be conducive for students to exercise autonomy for intrinsic motivation to occur. This is mainly because students are not given the opportunity to choose what they want to learn as the curriculum and syllabus have been determined by higher authorities. Moreover, for students to be intrinsically motivated, a lesson's content and a task must be appealing and exciting. Unfortunately, most school tasks and activities do not fulfil this requirement. Hence teachers are urged not to always depend on intrinsic motivation to foster learning (Brophy, 2004). Researchers are urged to design classroom environment to nurture students' motivation toward mathematics (Damrongpanit, 2019; Schukajlow et al., 2017).

Therefore, to incorporate motivation into instructional design, one must first recognise that motivation is a complex and multifaceted construct. As described by Keller (2010), it includes emotional affects, physiological reactions, behavioural responses, and cognitive processes. Accordingly, motivation has been conceptualised by aggregating several motivational theories to derive the Attention, Relevance, Confidence, Satisfaction (ARCS) motivational model (Keller, 2010). The model bridges the gap between motivational theories and their application in teaching and learning to enhance students' motivation to learn and solve students' motivational problem. The model is further discussed in the next section.

On the other hand, the Ministry of Education Malaysia purchased the license of Geometer's Sketchpad (GSP), a geometrical software, to encourage the use of technology in the teaching and learning of mathematics (Leong, 2014). GSP is a dynamic geometry software that can be used to create, explore, and analyse a broad range of mathematical concepts such as geometry, algebra, calculus, and trigonometry (Jackiw, 1991). Hence this study is framed in the context of technology-enhanced learning classroom as the specialised software is available in Malaysian public schools and was utilised in this study. This study, therefore, aims to explore the effects of the motivational strategies offered by the ARCS model, on Malaysian students' motivation towards mathematics in a technology-enhanced learning (TEL) classroom.

\section{LITERATURE REVIEW}

\section{ARCS Motivational Adaptive Instruction (MAI) in a Technology-Enhanced Learning Context}

The ARCS model (Keller, 2010) aggregates different motivational concepts and theories into four main motivational categories: attention, relevance, confidence, and satisfaction, consequently conceptualising the motivation construct. Motivational adaptive instruction refers to a teaching approach that combines both instructional and motivational plans to improve motivation to learn (Park \& Lee, 2004). Taken together, ARCS motivational adaptive instruction refers to the adaptation of the motivational strategies from the ARCS model into an instructional design plan.

In the ARCS model, attention is associated with several concepts, such as arousal theory, curiosity, and boredom (Keller, 2010). From the in-depth review of the literature done by Keller (2010), boredom is formulated as stimulation to act is at subpar levels. Moreover, the repetitive presentation of information can be the potential cause of boredom in the classroom. Therefore, it is crucial to have various presentation ways to sustain students' attention and interest in the learning content. Keller (2010) posits two motivational 
strategies in the ARCS model for getting students' attention - perceptual arousal, which creates curiosity via novelty stimuli, and inquiry arousal, which is about using questions to nurture thinking challenges.

In the model, relevance was conceptualised as people's perceptions of attraction or interest towards the task outcomes which are affected by their own goals, motives, and values. A sense of relevance usually occurs only when the learning content is perceived as having utility value (Wigfield \& Eccles, 2000). Therefore, Keller (2010) suggests that teachers and instructional designers can stimulate motivation to learn by linking learning content to students' intrinsic interest or situational interest.

Confidence was conceptualised as people's expectancies for success (Keller, 2010). Besides, he posits that the central issue concerning confidence in this model is people's perceptions of control on the consequences of their behaviour (Keller, 2010). Learners who lack confidence would attribute tasks failure to their ability which they perceive as a stable characteristic (Weiner, 1985). Students need to believe that change is possible in order for them to be motivated in learning (Hodges, 2004). Therefore, teachers are urged to help students recognise that effort is the reason for success by attributing students' achievement to their effort instead of ability (Keller, 2010).

It is argued that a sense of satisfaction is essential for continuing motivation, whereby providing feedback to students is helpful for building their positive motivation and crushing motivation (Keller, 2010). The type of feedback whether it is positive or negative will condition the learning environment where the teacher is a stimulus for the conditions for behaviour contingency regulation (Pavlov, 1906; Skinner, 1953). In addition, a sense of dissatisfaction or unfairness occurs when one perceives themselves as underpaid whereby people measure equity based on output to input subjectively (Adams, 1965). In classroom learning context, similar comparison can occur regarding exam grades, attention from teachers, examined and taught content in the course. Therefore, to make students satisfied with the learning environment, Keller (2010) advises teachers to be consistent in setting objectives, course content and examination as well as to be fair in classroom management so as not to favour a particular student.

Previous studies has shown the utility of the ARCS model in motivational design. Song and Keller (2001) adapted the ARCS motivational design in the computer-assisted instruction (CAI) classroom. The study showed that the interventions had improved students' overall motivation and attention. Besides, the ARCS motivational adaptive instructions improved both motivation and learning performance in the studies conducted by Gabrielle (2003), and Huett et al. (2008). Chang et al. (2016) also integrated the ARCS-based messages in mobile inquiry-based learning for undergraduate students in English as a Foreign Language course. They discovered an increase in the intervention group's motivational level; however, the improvement was not observed in their achievement. Similar results were found in Hodges and Kim's (2013) study in employing the ARCS model to design a motivational video as an intervention for non-mathematics major students. The results indicated that students' attitudes towards mathematics improved due to the treatment but did not detect any significant improvement in students' mathematics achievement. It can be seen that the motivational strategies in the ARCS model have the potential in enhancing students' motivation to learn and learning performance. However, the results vary across classrooms and contexts.

\section{Motivation in Mathematics Learning}

In mathematics education, there is inconsistency in how motivation is employed, and it varies from one study to another. In most mathematical research, self-efficacy is associated with motivation about cognitive engagement in mathematical tasks (Gilbert, 2016), motivational aspects in technology-based activities (Greefrath et al., 2018; Star et al., 2014) and project-based learning in secondary education (Holmes \& Hwang, 2016; Lainufar et al., 2021). Mathematics self-efficacy was conceptualised as students' perceptions of their competency to solve or perform mathematical tasks (Hannula et al., 2016; OECD, 2014; Skaalvik et al., 2015).

Utility value, which is a part of the expectancy-value theory (Wigfield \& Eccles, 2000), has also been covered in mathematical research on motivation (Gilbert, 2016; Holmes \& Hwang, 2016; Thien \& Ong, 2015). In PISA 2012 , instrumental motivation referred to students' perceptions of mathematics' utility value in their future 
careers. Moreover, Gilbert (2016) revealed that utility and mastery-approach goals in which the learning motivation emphasised on mathematics comprehension were only connected to the mathematical tasks that required higher cognitive engagement. Further, Holmes and Hwang (2016) explained that the affordance of project-based learning activities for providing utility value of mathematics improved students' intrinsic motivation as students were solving real-world problems. Emotions are often associated with motivation in mathematics education et al., 2017) or math anxiety as well (Pizzie \& Kraemer, 2021).

\section{Related Work}

In the Malaysian context, the ARCS model has been utilised in both technology-enhanced learning and mathematics classroom. Firstly, Abu Bakar et al. (2010) carried out a true experimental study to investigate students' motivation in learning mathematics by employing the ARCS model in two different technologyenhanced learning classrooms. The study implemented two different types of geometrical software: GeoGebra and V-Transformation. The findings showed that students were motivated in both classrooms, whereas the integration of V-Transformation had successfully gained students' attention and created a sense of relevance for students. Leong (2015) employed the ARCS motivational strategies and Geometer's Sketchpad to investigate the instructional effects on Malaysian Form Four students' motivation and geometry achievement in an exploratory case study. The study included only one intact classroom, which comprises 24 students and reported that students' motivation and geometry achievement significantly improved after the intervention. However, a point of contention in Leong's (2015) findings concerns the attribution of improvement in students' motivation - whether it was the motivational adaptive instructions or the novelty of technology that made the difference. The study also reported that students mentioned the integration of technology in learning mathematics created a sense of novelty and made them excited to learn. It was also hard to compare geometry achievement and motivation by using a single group of participants in the oneoff case study. This difficulty was because all the study participants had not learned the relevant geometry topic before the intervention. Hence, it is highly likely for their geometry achievement to improve after they had attended the mathematics lessons, with or without the intervention. This study will contribute to the existing knowledge by exploring the effects of the ARCS intervention using a quasi-experimental research design in a Malaysian context, and an understanding of students' motivation towards mathematics.

\section{OBJECTIVE OF THE STUDY}

The study's objective is to explore the effects of motivational adaptive instruction on Malaysian students' motivation towards mathematics learning in a technology-enhanced learning classroom. Specifically, this study aimed to answer the following research questions:

1. What is the Malaysian students' motivational profile towards mathematics in a technology-enhanced learning environment?

2. Does the motivational adaptive instruction have an effect on students' motivation towards mathematics learning environment?

3. Is there any relationship between motivation and mathematics performance among Malaysian students in a technology-enhanced learning environment?

\section{METHODS}

\section{Research Design and Participants}

A quasi-experimental non-equivalent control group with pre-test and posttest design (Campbell \& Stanley, 1963) was conducted with an experimental and a comparison group. This design is adopted based on the purpose of research in exploring treatment effects of the ARCS motivational adaptive instruction, that is, to establish a possible causal relationship between the intervention and students' motivation towards mathematics. The study was carried out for two weeks during which the administration of pre-test, post-test and treatments were conducted. 
Table 1. Discrimination index for the mathematics test

\begin{tabular}{llll}
\hline Item No. & Discrimination Index & Interpretation & Results \\
\hline 1 & 0.13 & Low positive discrimination & $\begin{array}{l}\text { Easy question but cannot differenciate } \\
\text { between high and low achievers } \\
\text { Good question }\end{array}$ \\
2 & 0.63 & Good positive discrimination & Easy question but acceptable \\
3 & 0.25 & Moderate positive discrimination & Good question \\
4 & 0.79 & Good positive discrimination & Good question \\
5 & 0.74 & Good positive discrimination & Easy question but acceptable \\
6 & 0.26 & Moderate positive discrimination & \\
\hline
\end{tabular}

Table 2. Difficulty index for the mathematics test

\begin{tabular}{llll}
\hline Item No. & Difficulty index & Classification of difficulty level & Results \\
\hline 1 & 0.96 & Too easy & Modify \\
2 & 0.60 & Moderate & Accept \\
3 & 0.43 & Moderate & Accept \\
4 & 0.38 & Moderate & Accept \\
5 & 0.30 & Moderate & Accept \\
6 & 0.20 & Too difficult & Modify \\
\hline
\end{tabular}

The participants were 40 Form Two students from two public national secondary schools in Selangor state, Malaysia. The two randomly chosen intact classes, with 20 participants in each class were randomly assigned to the experimental or comparison conditions. The study's instructional context is that both groups of students would receive mathematics instructions for the same mathematics topic, i.e., Loci in Two Dimensions - a chapter in Form Two (Grade 8) mathematics syllabus (Ministry of Education Malaysia, 2002). However, two groups will receive two different types of mathematics instructions, which will be discussed in the treatments section.

\section{Instruments}

A questionnaire and a mathematics test were administered to measure motivation and mathematics performance, respectively. The Course Interest Survey (CIS) comprising 34 items developed following the ARCS model by Keller and Subhiyah (1993) was adapted to measure students' motivation towards mathematics. It should be reiterated that the motivation construct in this study was constituted from the four subscales of motivation in the ARCS model, which are measured by the CIS, namely, attention (8 items), relevance ( 9 items), confidence ( 8 items), and satisfaction ( 9 items). It is a five-point Likert scale, ranging from $1=$ Not True to $5=$ Very True. There are nine negative items in the instrument which were reverse-scored before the scores were computed at the data analysis stage.

Mathematics performance was measured by a mathematics test that assessed the topic taught in this study. The test comprises six open-ended questions with a total minimum score of zero and a maximum score of 20. Nine lessons of mathematics class with 30 minutes for each lesson were administered in this study. Table 1 shows the discrimination index for every item in the mathematics test. All items have good or positive discrimination index except for the first item which has a low positive discrimination index after referring to the rule of thumb by Johari et al. (2011). Table 2 shows the difficulty index for all the items and the rule of thumb by Johari et al. (2012) suggested Items 1 and 6 should be modified. However, all items are retained because a good test should comprise a mixture of easy and difficult questions.

The Course Interest Survey's content validity was established through a panel of experts comprising an educational psychologist, and an expert in educational technology, while the motivational adaptive instruction and the mathematics test was validated by two experienced mathematics teachers. The experts identified and modified double- and multi-barrelled items, and they recommended modifications to some words and phrases to align them to the objectives of this study. Modifications to the items were made with written permission from the respective authors. The reliability of the CIS was established with Cronbach's alpha value at .84 , which is categorised as highly reliable, according to Cohen et al. (2007). For the mathematics test, the item-level content validity index (I-CVI) and scale-level content validity index are both 
Table 3. The schedule for data collection and treaments

\begin{tabular}{lll}
\hline Week & \multicolumn{2}{l}{ Data collection and treatments } \\
\cline { 2 - 3 } & Experimental group & Comparison group \\
\hline Week 1 & $\bullet$ Administration of the CIS pre-test (Day 1) & $\bullet$ Administration of the CIS pre-test (Day 1) \\
& - Audience analysis (Day 1) & $\bullet$ Four mathematics lessons \\
Week 2 & - Four mathematics lessons & $\bullet$ Three mathematics lessons \\
& - Three mathematics lessons & $\bullet$ Administration of the posttest (Day 14) \\
& $\bullet \quad$ Mdministration of the CIS posttest (Day 14) & $\bullet$ Mathematics test (Day 14) \\
\hline
\end{tabular}

1, which meet the satisfactory level (Yusoff, 2019), and thus the scale of mathematics test has achieved satisfactory level of content validity.

\section{Procedure}

Given that previous studies have provided evidence that two weeks interventional period can improve students' motivational attitudes towards mathematics (Erbas \& Yenmez, 2011; Hodges \& Kim, 2013), this study was conducted for two weeks with pre- and post-tests. Table 3 shows the procedure for data collection and treatments. During Week 1, the week's first mathematics lesson was used to administer the pre-test of $\mathrm{CIS}$. For the experimental group, the researchers carried out audience analysis during the first lesson. As a part of the intervention, the researcher displayed two brain-teaser type of questions that required mathematics solutions. Students' responses to the questions posed and their approaches to solving the puzzle were observed. The observation served as the input to the motivational adaptive instruction for the experimental group. The treatments were carried out for the remaining four lessons in Week 1 and three lessons in Week 2. Before the post-test, the instruction for the mathematics chapter was completed. During the last two lessons in Week 2 on day 14 of the study, CIS post-test and mathematics test were administered to both groups of participants.

\section{Treatments}

This study involved two types of treatments: motivational adaptive instructions and conventional instructions for experimental and comparison groups, respectively. The intervention, which is the MAl, was designed using the guideline provided by the Cheng and Yeh's (2009) framework. The framework has adapted the ARCS motivational model into Morrison and colleagues' (2004) instructional model, making it a suitable guideline for the systematic design process for the motivational adaptive instruction in this study. As Keller (2010) emphasised, MAI is a problem-solving process, which means it is designed to solve students' motivational problems, and thus, one size does not fit all. Therefore, audience analysis as one of the steps in the systematic design process is a crucial procedure where students' motivational and instructional problems and school and classroom learning environments were analysed to make better pedagogical decisions for instructional planning. As stated in Table 1, audience analysis was conducted on Day 1 for the experimental group. Besides observing students, the audience analysis has also included the input from participants' mathematics teacher about her experience in handling students' mathematics learning and her observation about students' motivation towards mathematics learning.

On the other hand, conventional instruction refers to the teaching approach that only intends to achieve the learning objectives. In this study, the conventional instructional plan was designed following the suggestions provided in the Form Two mathematics textbook (Ministry of Education Malaysia, 2002). Motivational strategies were not purposely integrated into this instructional plan.

The most distinctive difference between motivational adaptive and conventional instruction is the mathematics teacher's perceptions of their role to motivate students. For instance, the MAl instructions were designed to create a task-oriented learning environment. This instruction encouraged students to try on mathematics computation, showed appreciation for students' efforts to learn although they might not be able to understand the term 'loci' entirely in the first lesson, and provided more real-life problems to promote a sense of relevance for students. 


\section{Utilisation of Geometer's Sketchpad (GSP) in Learning Environment}

Both sessions of instruction are carried out in a technology-enhanced learning environment in which Geometer's Sketchpad was used in the classrooms. Geometer's Sketchpad is a dynamic geometry software which was developed and has been widely used to enhance the understanding of geometric thinking in the mathematics classroom (Chew \& Lim, 2013). Using GSP, a geometrical figure can be drawn on the computer screen; it can be 'dragged' in such a way that the geometrical relation of the construction is maintained while the figure is changing (Jones et al., 2009). On this notion, such geometrical software is known as dynamic.

In this study, GSP's dynamic feature was utilised in visualising the definition of a locus, which was an abstract concept for the students. The feature of animating moving points in GSP was used to illustrate the path of a moving point in four different conditions which was known as a locus. These conditions include a point moving at a constant distance from a fixed point; at a equidistance from two fixed points; at a constant distance from a straight line; and, at equidistant from two intersecting lines (Ministry of Education Malaysia, 2002). An example of the GSP teaching material is included in Appendix A. Similar teaching examples were prepared for the four different conditions of moving points in this chapter.

\section{Data Analysis}

All data analyses were conducted on SPSS 22 to answer the three research questions. An alpha level of .05 was established a priori to determine statistical significance for this study. It is considered a good value and provides a low risk of errors without demanding enormous treatment effect (Gravetter \& Wallnau, 2014). For the first research question, descriptive statistics were performed using the pre-test results from both groups. Therefore, the Malaysian students' motivational profile towards mathematics was captured before the treatments took place. The analysis of covariance (ANCOVA) was performed to answer the research question two, whether the treatment affects motivation. ANCOVA was chosen to analyse the intervention's effectiveness because it could reduce the initial differences between the experimental and comparison groups by controlling the pre-test scores for the dependent variables (Fraenkel et al., 2012).

Testing of ANCOVA assumptions was conducted to check for (i) normality, (ii) homogeneity of variances, (iii) measurement of the covariate, (iv) reliability of the covariate, (v) linearity, and (vi) homogeneity of regression slope. The distribution of mean for all the variables was found to be normal as the p-value for each of the variables and groups was more than .05 as per (Pallant, 2011). Most of the skewness and kurtosis values ranged from -1.00 and +1.00 which are considered as excellent, while some values ranged from -2.00 to +2.00 which are considered as acceptable (George \& Mallery, 2003). Therefore, the data collected for each variable in every group met the normality assumptions. Next, p-value for the Levene's test is .65 which suggested the homogeneity of variances was met. Next, the covariate was measured prior to the experimental manipulation as students' motivation was measured before the treatment. Meanwhile, the realibility of the covariate was a Cronbach's alpha value of .89, which is very highly reliable according to Cohen et al. (2007). Also, there was a linear relationship between the dependent variable and the covariate for both groups by using a simple scatter graph. Lastly, the significant value for the interaction between the covariate and the groups was .57, which was safely above .50 (Pallant, 2011), and hence the assumption of homogeneity of regression slopes was not violated. As such, all assumptions for tesing of ANCOVA were fulfilled.

The CIS pre-test scores for both groups were taken as the covariate, to control the initial differences of motivational levels between the two intact groups. Subsequently, the analysis focused on whether one group had a higher mean scores than the other after the treatments to examine the interventions' impact on students' motivation. Lastly, the relationship between motivation and mathematics performance was explored using the Pearson product-moment correlation coefficient. The rule of thumb by Cohen et al. (2007) was used for interpreting the results of $r$ values in this study. 
Table 4. Distribution of mean scores on the CIS scale

\begin{tabular}{|c|c|c|c|c|c|c|c|}
\hline \multirow{2}{*}{ Scale } & \multicolumn{5}{|c|}{ Percentage (\%) } & \multirow{2}{*}{$M$} & \multirow{2}{*}{$S D$} \\
\hline & Not True & Slightly True & Moderately True & Mostly True & Very True & & \\
\hline Attention & 9.7 & 12.5 & 25.6 & 24.7 & 27.5 & 3.48 & 0.70 \\
\hline Relevance & 3.6 & 11.7 & 17.5 & 28.6 & 38.6 & 3.87 & 0.61 \\
\hline Confidence & 9.4 & 11.6 & 25.6 & 25.9 & 27.5 & 3.51 & 0.50 \\
\hline Satisfaction & 16.4 & 11.9 & 20.8 & 21.1 & 29.7 & 3.36 & 0.66 \\
\hline Overall motivation & 9.78 & 11.91 & 22.21 & 25.07 & 31.03 & 3.56 & 0.54 \\
\hline
\end{tabular}

Note: Not True (1); Slightly True (2); Moderately True (3); Mostly True (4); Very True (5)

Table 5. Descriptive statistics of overall motivation at pre-and post-test

\begin{tabular}{llcccc}
\hline \multirow{2}{*}{ Scale } & \multirow{2}{*}{ Group } & \multicolumn{2}{c}{ Pre-test (Time 1) } & \multicolumn{2}{c}{ Post-test (Time 2) } \\
\cline { 3 - 6 } & & $M$ & $S D$ & $M$ & $S D$ \\
\hline Overall motivation & Experimental group & 3.38 & 0.62 & 3.57 & 0.37 \\
& Comparison group & 3.73 & 0.39 & 3.54 & 0.37 \\
\hline
\end{tabular}

\section{RESULTS AND FINDINGS}

\section{RQ1: What is the Malaysian Students' Motivational Profile Towards Mathematics in a Technology- Enhanced Learning Environment?}

Table 4 shows the students' overall mean score for motivation towards mathematics was 3.56, with a standard deviation of 0.54 . In particular, the students scored the highest on the relevance subscale $(M=3.87$, $S D=0.61$ ) where $67.2 \%$ of the students had positive $(28.6 \%)$ or highly positive $(38.6 \%)$ views on the relevance of mathematics to their life. It was then followed by the confidence subscale $(M=3.51, S D=0.50)$ where over half of the students (53.4\%) were confident about mathematics learning.

On the other hand, the attention $(M=3.48, S D=0.70)$ and satisfaction $(M=3.36, S D=0.66)$ subscales were placed at the bottom half of the students' scores. There were $22.2 \%$ of students who had a low attention level during mathematics lessons. These students consisted of $9.7 \%$ who thought the lessons were not stimulating and $12.55 \%$ who found the lessons to be slightly stimulating. Within the satisfaction subscale, slightly more than a quarter of the students (28.3\%) did not feel satisfied in mathematics learning with $16.4 \%$ choosing 'Not True' and $11.9 \%$ opting for 'Slightly True' statements about satisfaction in mathematics learning. However, in general, the overall motivation $(M=3.56)$ towards mathematics was well above the scale's mid-point (3.00).

\section{RQ2: Does the Motivational Adaptive Instructions have an Effect on Students' Motivation Towards Mathematics Learning Environment?}

Table 5 shows the descriptive statistics of overall motivation at pre-and posttest. The overall motivation mean scores of the experimental group were lower than that of the comparison group at Time 1 but became higher than those of the comparison group at Time 2. Meanwhile, the experimental group's overall motivation score showed a modest increment from Time 1 to Time 2. On the other hand, there was a drop in overall motivation score for the comparison group from Time 1 to Time 2 . There were positive changes in motivation for the experimental group while the comparison group, in contrast, showed negative changes.

Independent samples $t$-tests were first performed to determine if there was a significant difference between the experimental group and the comparison group at Time 1 and Time 2 for overall motivation score. At Time 1 , there was a significant difference for the mean score of overall motivation between the experimental group $(M=3.38 ; S D=0.62)$ and the comparison group $(M=3.73 ; S D=0.39)$ with $t(38)=-2.15, p<.05$. The results suggested that the motivation level of the experimental and comparison group was different before the treatments. In contrast, there was no significant difference for the overall motivation means score between the experimental group $(M=3.57, S D=0.37)$ and the comparison group $(M=3.54, S D=0.37), t(38)=.31, p>.05$ 
Table 6. Analysis of covariance for overall motivation

\begin{tabular}{lccccc}
\hline Sources & Sum of squares & $\mathrm{df}$ & Mean square & $F$ & $p$ \\
\hline Corrected model & .94 & 2 & .47 & .92 & .15 \\
Covariate & .92 & 1 & .02 & 8.19 & .01 \\
Group & .18 & 1 & .18 & .22 \\
Error & 4.18 & 37 & .11 & \\
Total & 510.05 & 40 & & \\
Corrected total & 5.11 & 39 & & \\
\hline
\end{tabular}

for Time 2. This indicates that the motivation level is similar for the experimental and comparison groups after the treatments.

On the other hand, paired-samples $t$-tests were conducted to evaluate if there was a significant difference between the overall motivation scores at Time 1 and Time 2, for both groups. There was no statistically significant difference between the overall motivation at Time 1 and Time 2 for the experimental group, $t$ (38) $=-1.68, p>.05$, and the comparison group, $t(38)=1.86, p>.05$. The paired sample t-tests suggested that students' overall motivation remained unchanged after the treatments. This indicated that the increment of motivation level from Time 1 to Time 2 shown in the experimental group, was not significant as well.

ANCOVA was conducted to evaluate the effectiveness of the intervention on the motivation towards mathematics. Testing of ANCOVA assumptions was conducted, and the assumptions were all met for the analysis. Table 6 presents the summary statistics of ANCOVA for students' overall motivation towards mathematics. The covariate, taken from the motivation pre-test scores, was significantly related to the motivation posttest scores, $F(1,37)=8.19, p<.50$, and partial eta squared $=.18$ indicated that the covariate explained 18 per cent of the variances in the post-test motivation scores. After controlling the effect of the students' motivation before the treatment, the adjusted mean score in the experimental group $(M=3.48, S E$ $=0.08$ ). However, the motivationally adaptive instruction had no significant effect on students' motivation after the effect of students' motivation before the treatment was controlled, $F(1,37)=1.58, p>.05$. The total unexplained variances in students' motivation were 5.11 units where the treatment and 4.18 explained only .94 unit were unexplained. The ANCOVA results indicate no changes in students' motivation after the treatments while their motivation before the treatment was controlled. Subsequently, ANCOVA was not conducted for the ARCS subscales because there was no significant effect of the intervention on overall motivation. This indicated it was not necessary to further investigate the effects on the intervention on the subscales.

\section{RQ3: Is There any Relationship Between Motivation and Mathematics Performance Among Malaysian Students in a Technology-Enhanced Learning Environment?}

The descriptive statistics of the mathematics performance among the 40 students were first explored. Figure 1 shows the histogram of the mathematics test scores. The full score of the mathematics test is 20 , the lowest score among the students is 3 and the highest is 18 . The mean score for the mathematics test is 9.08 with a standard deviation of 3.88; this indicated that the students did not pass the mathematics test as a whole.

The relationship between motivation and mathematics performance was explored using the motivation scores collected at Time 2 and the mathematics test administered after the treatments were completed. No significant relationship was established between mathematics and mathematics performance for the 40 students, at $r=.23$ with $p=0.16$. The strength of the relationship was considered small (Cohen et al., 2007), and there was not much overlap between the two variables as only $5.3 \%$ of variances shared between them. 


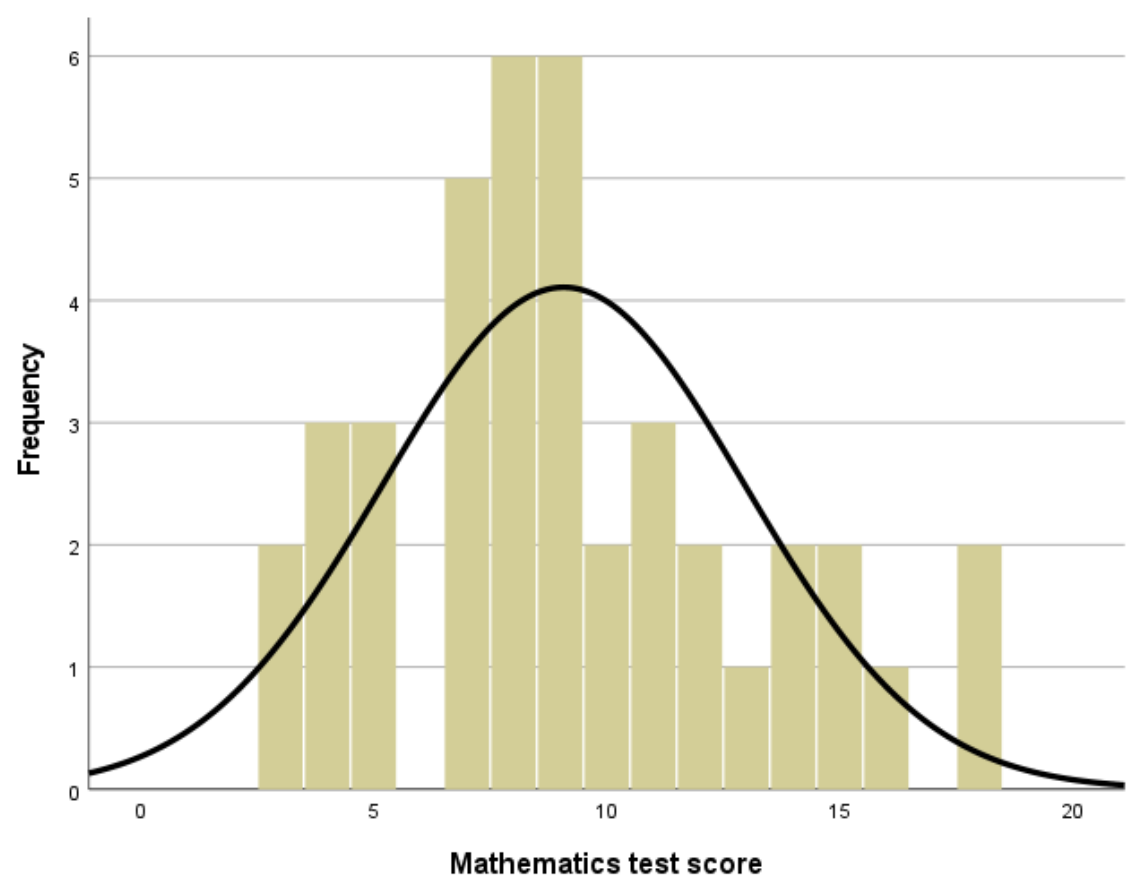

Figure 1. Histogram of mathematics test score for 40 students

\section{DISCUSSION AND CONCLUSION}

The motivational profile descriptive analysis showed that the Form Two students' motivational level in this study was slightly above average. Among the four subscales, the relevance subscale had the highest scores. This finding indicates that Malaysian lower secondary school students do understand the practicality and usefulness of learning mathematics. The confidence subscale ranked second among the four subscales, which was slightly above average as well. As per the conceptualisation of confidence in the ARCS model, the students had an above-average level of expectations for mathematics learning success. The attention level was just above average, suggesting that the mathematics lessons might not be appealing and exciting. However, it might be just adequate to engage students, and students' attention was moderately stimulated. Lastly, satisfaction ranked at the lowest among the four subscales in the ARCS model. This indicates that students might just have an average experience with mathematics lessons. This is somewhat consistent with the results from PISA 2012, whereby Malaysian 15-year-old students were reported to have mathematics anxiety that was above the OECD average (OECD, 2013; Thien \& Ong, 2015). It is more likely that students did not experience the excitement in the learning process, making the mathematics lessons an unsatisfying stimulant for students. Also, it is possible that students experienced discomfort when they were asked to conjecture what is the possible path of a moving point under the given condition. The discomfort may have come from the low tolerance with ambiguity when learning mathematics in which students may prefer teacher-directed monologic approaches (Murphy et al., 2020). This could be one of the possible reasons for students to feel dissatisfied with the lessons, however, students' preferences of teaching approaches were not explored in this study. In short, Malaysian lower secondary school students' motivation towards mathematics was just above average in general.

In this technology-enhanced learning context, despite the improved motivation mean scores for the experimental group after the interventions, ANCOVA showed that the improvement was not significant. This reflects that the motivationally adaptive instruction was not effective in improving students' motivation towards mathematics significantly. This finding is contrary to that of Leong (2015) and Abu Bakar and colleagues' work (2010) which showed that the ARCS motivational strategies had improved Malaysian students' motivation towards mathematics in a technology-enhanced learning classroom. 
There are several possible explanations for this finding. Firstly, the two-week intervention duration may have been insufficient for the experimental group to experience substantial gains in a construct as fundamental and multidimensional as motivation. Star and colleagues (2014) explained that it is unlikely to observe a change in a complex construct such as self-efficacy in a short interventional programme. The experimental group showed improvement in the motivation after the intervention treatment, but it was not significant. We could only, therefore, conjecture that substantial difference may be detected if the intervention period was longer. Also, students in the comparison group underwent two weeks of conventional instructions to achieve the learning objective. The mastery of the comparison group's learning content may have reduced the possible significant difference of overall motivation between the comparison and experimental groups. If this is the case, the mastery of learning content could have motivated students without motivational strategies. Regarding the use of technology in the teaching and learning of mathematics, both groups in this study have used GSP to understand an abstract mathematics concept. This study attest to the necessity to further design interventional studies in improving motivation in learning mathematics in a technologyenhanced learning environment (Schukajlow et al., 2017).

Nonetheless, this does not mean the ARCS motivational strategies could not work in the Malaysian context. Instead, it implies the work of incorporating motivational strategies into instruction requires more extensive planning and consideration of many other factors that could affect students' motivation towards mathematics. For instance, students' fear of failure, self-efficacy or achievement-goal orientation (Pantziara \& Philippou, 2015). Factors like mathematics teachers' self-efficacy was associated with the classroom mastery orientation which is a type of motivation (Lazarides et al., 2018).

Lastly, it was found that the relationship between motivation and mathematics performance is positive but not closely related. This is contrary to the past studies that found motivation to be strongly related to mathematics performance (Mullis et al., 2012; Pantziara \& Philippou, 2015). It suggests that in the Malaysian context, motivation is not closely related to mathematics performance. This may be explained by Leung's (2006) speculation in which East Asian's culture of being examination driven, consequently, the significance of public examination, has made motivation a less critical factor in performing well in mathematics. Besides, the virtue of being modest with humility in recognising self-abilities might have lowered one's reflection on their confidence as well (Leung, 2006). However, this does not mean that motivation is not crucial in Malaysian students' mathematics learning. For students who are not focusing on performing well in the examination, stimulating and enhancing their motivation to learn becomes a critical aspect of mathematics instructions. As advocated by Schukajlow and colleagues (2017), it is important to continue studying about students' motivation and cognitive variables like cognitive performance.

In conclusion, Malaysian lower secondary school students' motivation towards mathematics was just above average, in a technology-enhanced learning context. Students were aware of the usefulness of mathematical knowledge while they might not be assertive on the perception of their ability in performing mathematical tasks. Although mathematics lessons might stimulate students' attention, they might not feel satisfied in the learning process. The ARCS motivational strategies require more time for the complex and multifaceted construct like motivation to develop and be improved in a technology-enhanced classroom in Malaysia. Although motivation does not significantly link to mathematics performance within this group of Malaysian students, it does not diminish the critical role of motivation in students' mathematics learning, especially for those who are relying on motivation to learn.

Author contributions: All authors were involved in concept, design, collection of data, interpretation, writing, and critically revising the article. All authors approve final version of the article.

Funding: The authors would like to thank the Research Management Centre of Universiti Putra Malaysia for funding this research project (GP-IPS/2017/9540000).

Declaration of interest: Authors declare no competing interest.

Data availability: Data generated or analysed during this study are available from the authors on request. 


\section{REFERENCES}

Abu Bakar, K., Mohd Ayub, A. F., Wong, S. L., \& Ahmad Tarmizi, R. (2010). Exploring secondary school students' motivation using technologies in teaching and learning mathematics. Procedia-Social and Behavioral Sciences, 2(2), 4650-4654. https://doi.org/10.1016/j.sbspro.2010.03.744

Adams, J. S. (1965). Inequity in social exhange. In L. Berkowitz (Ed.), Advances in experimental social psychology (Vol. 2, pp. 267-299). Academic Press. https://doi.org/10.1016/S0065-2601(08)60108-2

Brophy, J. (2004). Motivating students to learn (Second). Erlbaum. https://doi.org/10.4324/9781410610218

Brophy, J. (2008). Developing students' appreciation for what is taught in school. Educational Psychologist, 43(3), 132-141. https://doi.org/10.1080/00461520701756511

Campbell, D. T., \& Stanley, J. C. (1963). Experimental and quasi-experimental designs for research.

Chang, C., Chang, C.-K., \& Shih, J.-L. (2016). Motivational strategies in a mobile inquiry-based language learning setting. System, 59, 100-115. https://doi.org/10.1016/j.system.2016.04.013

Cheng, Y.-C., \& Yeh, H.-T. (2009). From concepts of motivation to its application in instructional design: Reconsidering motivation from an instructional design perspective. British Journal of Educational Technology, 40(4), 597-605. https://doi.org/10.1111/j.1467-8535.2008.00857.x

Chew, C. M., \& Lim, C. S. (2013). Enhancing primary pupil's geometric thinking thtough phased-based instruction using the Geometer's Sketchpad. Asia Pacific Journal of Educators and Education, 28, 3351. http://eprints.usm.my/34714/1/apjee28_2013_art3_33_51.pdf

Cohen, L., Manion, L., \& Morrison, K. (2007). Research methods in education (6th ed.). Routledge. https://doi.org/10.4324/9780203029053

Damrongpanit, S. (2019). From modern teaching to mathematics achievement: The mediating role of mathematics attitude, achievement motivation, and self-efficacy. European Journal of Educational Research, 8(3). https://doi.org/10.12973/eu-jer.8.3.713

Deci, E. L., \& Ryan, R. M. (2000). The "what" and "why" of goal pursuits: Human needs and the selfdetermination of behavior. Psychological Inquiry, 11(4), 227-268. https://doi.org/10.1207/S15327965PLI1104_01

Deci, E. L., \& Ryan, R. M. (2008). Self-determination theory: A macrotheory of human motivation, development, and health. Canadian Psychology/Psychologie Canadienne, 49(3), 182-185. https://doi.org/10.1037/a0012801

Dweck, C. S. (2017). From needs to goals and representations: Foundations for a unified theory of motivation, personality, and development. Psychological Review, 124(6), 689-719. https://doi.org/10.1037/rev0000082

Erbas, A. K., \& Yenmez, A. A. (2011). The effect of inquiry-based explorations in a dynamic geometry environment on sixth grade students' achievements in polygons. Computers \& Education, 57(4), 24622475. https://doi.org/10.1016/j.compedu.2011.07.002

Fraenkel, J. R., Wallen, N. E., \& Hyun, H. H. (2012). How to design and evaluate research in education (8th ed.). McGraw-Hill.

Gabrielle, D. (2003). The effects of technology-mediated instructional strategies on motivation, performance, and self-directed learning. EdMedia + Innovate Learning, 2568-2575. http://www.learntechlib.org/p/14267/ 
Gilbert, M. C. (2016). Relating aspects of motivation to facets of mathematical competence varying in cognitive demand. The Journal of Educational Research, 109(6), 647-657. https://doi.org/10.1080/00220671.2015.1020912

Gravetter, F. J., \& Wallnau, L. B. (2014). Essentials is statistics for the behavioral sciences. Jon-David Hague.

Greefrath, G., Hertleif, C., \& Siller, H.-S. (2018). Mathematical modelling with digital tools-A quantitative study on mathematising with dynamic geometry software. ZDM, 50(1-2), 233-244. https://doi.org/10.1007/s11858-018-0924-6

Hannula, M. S., Di Martino, P., Pantziara, M., Zhang, Q., Morselli, F., Heyd-Metzuyanim, E., Lutovac, S., Kaasila, R., Middleton, J. A., Jansen, A., \& Goldin, G. A. (2016). Attitudes, beliefs, motivation and identity in mathematics education: An overview of the field and future directions. Springer International Publishing. https://doi.org/10.1007/978-3-319-32811-9

Hodges, C. B., \& Kim, C. (2013). Improving college students' attitudes toward mathematics. TechTrends, 57(4), 59-66. https://doi.org/10.1007/s11528-013-0679-4

Holmes, V.-L., \& Hwang, Y. (2016). Exploring the effects of project-based learning in secondary mathematics education. The Journal of Educational Research, 109(5), 449-463. https://doi.org/10.1080/00220671.2014.979911

Huett, J. B., Kalinowski, K. E., Moller, L., \& Huett, K. C. (2008). Improving the motivation and retention of online students through the use of ARCS-based e-mails. American Journal of Distance Education, 22(3), 159-176. https://doi.org/10.1080/08923640802224451

Ismail, N. A., \& Awang, H. (2012). Students factors and mathematics achievement: Evidence from TIMSS 2007. Eurasia Journal of Mathematics, Science \& Technology Education, 8(3), 249-255. https://doi.org/10.12973/eurasia.2012.843a

Jackiw, N. (1991). The Geometer's Sketchpad [Computer software]. Key Curriculum Press.

Johari, J., Sahari, J., Wahab, D. A., Abdullah, S., Abdullah, S., Omar, M. Z., \& Muhamad, N. (2011). Difficulty index of examinations and their relation to the achievement of programme outcomes. Procedia-Social and Behavioral Sciences, 18, 71-80. https://doi.org/10.1016/j.sbspro.2011.05.011

Johari, J., Wahab, D. A., Ramli, R., Saibani, N., Sahari, J., \& Muhamad, N. (2012). Identifying student-focused intervention programmes through discrimination index. Procedia - Social and Behavioral Sciences, 60, 135-141. https://doi.org/10.1016/j.sbspro.2012.09.359

Jones, K., Mackrell, K., \& Stevenson, I. (2009). Designing digital technologies and learning activities for different geometries. In C. Hoycles \& J. B. Lagrange (Eds.), Mathematics education and technologyrethinking the terrain: The 17th ICMI study (pp. 47-60). Springer. https://doi.org/10.1007/978-1-44190146-0_4

Keller, J. (2010). Motivational design for learning and performance. Springer. https://doi.org/10.1007/978-14419-1250-3

Keller, J. M., \& Subhiyah, R. (1993). Course interest survey. Florida State University.

Kim, C., \& Keller, J. M. (2010). Motivation, volition and belief change strategies to improve mathematics learning: Motivation, volition and belief change strategies. Journal of Computer Assisted Learning, 26(5), 407-420. https://doi.org/10.1111/j.1365-2729.2010.00356.x

Lainufar, Mailizar, M., \& Johar, R. (2021). Exploring the potential use of GeoGebra augmented reality in a project-based learning environment: The case of geometry. Journal of Physics: Conference Series, 1882(1), 012045. https://doi.org/10.1088/1742-6596/1882/1/012045 
Lazarides, R., Buchholz, J., \& Rubach, C. (2018). Teacher enthusiasm and self-efficacy, student-perceived mastery goal orientation, and student motivation in mathematics classrooms. Teaching and Teacher Education, 69, 1-10. https://doi.org/10.1016/j.tate.2017.08.017

Leong, C. K. (2014). Educating the educators: Technology-enhanced mathematics teaching and learning. Proceedings of the 19th Asian Technology Conference in Mathematics. Asian Technology Conference in Mathematics, Yogyakarta.

Leong, K. W. (2015). The effects of instruction using the ARCS model and Geogebra on upper secondary students' motivation and achievement in learning combined transformation. Asia Pacific Journal of Educators and Education, 30, 141-158.

Leung, F. K. S. (2006). Mathematics education in East Asia and the West: Does culture matter? In F. K. S. Leung, K.-D. Graf, F. J. Lopez-Real, \& International Commission on Mathematical Instruction (Eds.), Mathematics education in different cultural traditions: A comparative study of East Asia and the West. Springer.

Ministry of Education Malaysia. (2002). Integrated curriculum for secondary schools: Form 2 Mathematics. Curriculum Development Centre.

Morrison, G. R., Ross, S. M., \& Kemp, J. E. (2004). Designing effective instruction (4th ed.). John Wiley \& Sons.

Mullis, I. V., Martin, M. O., Foy, P., \& Arora, A. (2012). TIMSS 2011 international results in mathematics. TIMSS \& PIRLS International Study Center, Boston College.

Murphy, C., Calder, N., Mansour, N., \& Abu-Tineh, A. (2020). Introducing WebQuests in mathematics: A study of Qatari students' reactions and emotions. International Electronic Journal of Mathematics Education, 15(3), em0603. https://doi.org/10.29333/iejme/8445

OECD, P. (2013). PISA 2012 results: Ready to learn: Students' engagement, drive and self-beliefs (Volume III).

OECD, P. (2014). Results: What students know and can do student performance in mathematics, reading and science (Volume I, Revised edition, February 2014). OECD.

Pallant, J. (2011). A step by step guide to data analysis using the SPSS program: SPSS Survival Manual. Allen Unwin.

Pantziara, M., \& Philippou, G. N. (2015). Students' motivation in the mathematics classroom. Revealing causes and consequences. International Journal of Science and Mathematics Education, 13(2), 27.

Park, O. C., \& Lee, J. (2004). Adaptive instuctional systems. In J. D. H (Ed.), Handbook of research for education communications and technology (pp. 651-684). Erlbaum.

Pavlov, I. P. (1906). The scientific investigation of the psychical faculties or processes in the higher animals. Science, 24(620), 613-619.

Pizzie, R. G., \& Kraemer, D. J. M. (2021). The association between emotion regulation, physiological arousal, and performance in math anxiety. Frontiers in Psychology, 12, 639448. https://doi.org/10.3389/fpsyg.2021.639448

Schukajlow, S., Rakoczy, K., \& Pekrun, R. (2017). Emotions and motivation in mathematics education: Theoretical considerations and empirical contributions. ZDM, 49(3), 307-322. https://doi.org/10.1007/s11858-017-0864-6

Skaalvik, E. M., Federici, R. A., \& Klassen, R. M. (2015). Mathematics achievement and self-efficacy: Relations with motivation for mathematics. International Journal of Educational Research, 72, 129-136. https://doi.org/10.1016/j.ijer.2015.06.008

Skinner, B. F. (1953). Science and human behavior. The Free Press. 
Song, S., \& Keller, J. M. (2001). Effectiveness of motivationally adaptive computer-assisted instruction on dynamic aspects of motivation. Educational Technology Research and Development, 49(2), 5-22.

Star, J. R., Chen, J. A., Taylor, M. W., Durkin, K., Dede, C., \& Chao, T. (2014). Studying technology-based strategies for enhancing motivation in mathematics. International Journal of STEM Education, 1(7), 119. International Journal of STEM Education, 1(7), 1-19.

Statistica (2018). Leading countries based on number of Instagram users as of July 2018. https://www.statista.com/statistics/578364/countries- with-most-instagram-users/

Thien, L. M., \& Ong, M. Y. (2015). Malaysian and Singaporean students' affective characteristics and mathematics performance: Evidence from PISA 2012. SpringerPlus, 4(1), 563. https://doi.org/10.1186/s40064-015-1358-z

Walter, J. G., \& Hart, J. (2009). Understanding the complexities of student motivations in mathematics learning. The Journal of Mathematical Behavior, 28(2-3), 162-170. https://doi.org/10.1016/j.jmathb.2009.07.001

Weiner, B. (1985). An attributional theory of achievement motivation and emotion. Psychological Review, 92, 548-573.

Wigfield, A., \& Eccles, J. S. (2000). Expectancy-value theory of achievement motivation. Contemporary Educational Psychology, 25(1), 68-81. https://doi.org/10.1006/ceps.1999.1015

Yusoff, M. S. B. (2019). ABC of content validation and content validity index calculation. Education in Medicine Journal, 11(2), 49-54. https://doi.org/10.21315/eimj2019.11.2.6

Correspondence: Su Luan Wong, Faculty of Educational Studies, Universiti Putra Malaysia, Malaysia.

E-mail: suluan@upm.edu.my 


\section{APPENDIX A}

An example of the GSP teaching material is shown below. The point 'Bicycle' will be selected, right clicked, and 'Animate Point' will be selected as shown in the snapshot below. After that, the path of the moving 'Bicycle' will be shown and that is the locus of the moving point.

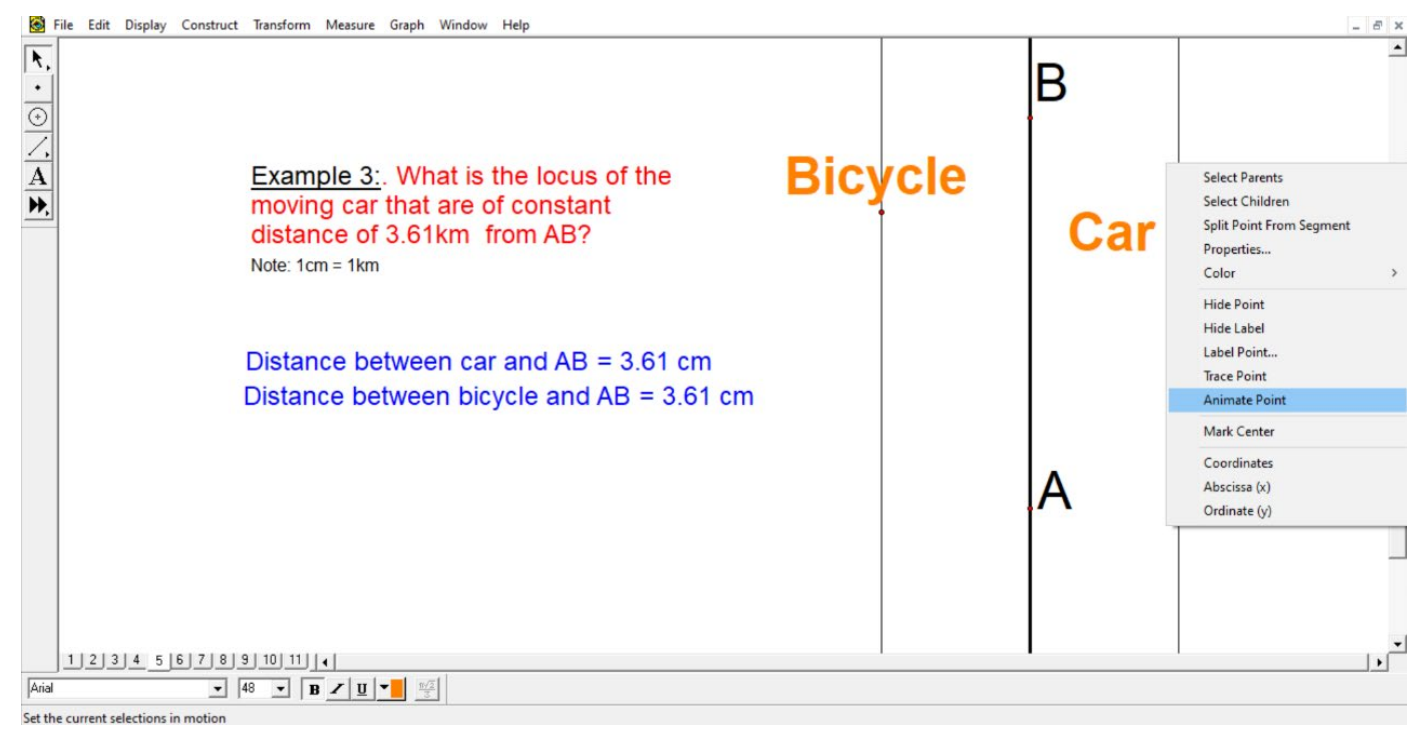

